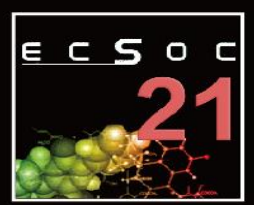

The 21st International Electronic Conference on Synthetic Organic Chemistry

1-30 November 2017

chaired by Dr. Julio A. Seijas Vázquez

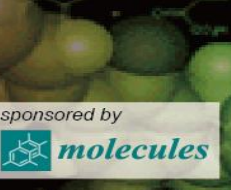

\title{
Green synthesis of quinazolinone derivatives by using a recyclable
}

\section{heteropoly acid catalyst}

\author{
Ali Maleki*, Jamal Rahimi and Razieh Firouzi-Haji \\ Catalysts and Organic Synthesis Research Laboratory, Department of Chemistry, Iran \\ University of Science and Technology, Tehran, Iran \\ *E-mail: maleki@iust.ac.ir
}

\begin{abstract}
In this study, we introduce an efficient method for the synthesis of quinazolinone derivatives in the presence of $\mathrm{H}_{5} \mathrm{PV}_{2} \mathrm{Mo}_{10} \mathrm{O}_{40} / \mathrm{SiO}_{2}$ polyoxometalate composite. Quinazolinone derivatives were successfully synthesized via one-pot multicomponent reactions strategy from aromatic aldehydes and anthranilamide. High products yield, short reaction times, simplicity of operation, simple work-up and easy purification are advantages of this approach.

Keywords: Heterogeneous catalyst, Heteropoly acid, Polyoxometalate, Quinazolinone.
\end{abstract}

\section{Introduction}

Design and application of acid catalysts in organic synthesis due to minimizing energy consumption and waste production have considered a lot of attention. Nowadays, the catalytic activity of heteropoly acids (HPAs) and related polyoxometalate (POMs) compounds have received great attention by organic chemists. These catalysts have outstanding advantages such as stable and strong acidity, high oxidation potential, redox characteristics and impressive sensitivity to light being environmentally and presenting fewer disposal problems 
[1]. Quinazolines are important class of nitrogen containing heterocycles with a bicyclic structure consisting of two fused six membered aromatic rings, which are valuable in the field of pharmaceutical chemistry because of their biological properties including anticancer, diuretic, anti-inflammatory, anticonvulsant and antihypertensive activities [2-4].

In continuation of our research on catalysis and organic reactions based on green chemistry [5-10], herein, $\mathrm{H}_{5} \mathrm{PV}_{2} \mathrm{Mo}_{10} \mathrm{O}_{40} / \mathrm{SiO}_{2} \mathrm{POM}$ composite was prepared and characterized according to published reports [11]. After that, the catalytic activity of synthesized catalyst was investigated in the synthesis of quinazolinone derivatives via one-pot multicomponent reactions strategy from aromatic aldehydes and anthranilamide (Scheme 1).

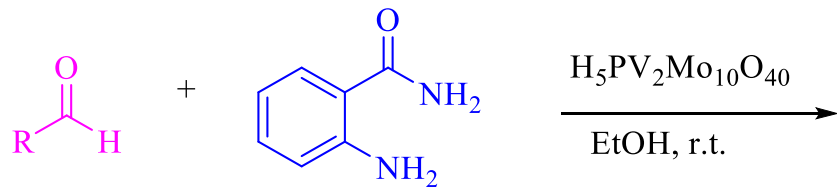<smiles>[R]c1nc2ccccc2c(=O)[nH]1</smiles>

Scheme 1. POM-catalyzed one-pot synthesis of 2-substituted quinazolinones.

\section{Experimental}

\subsection{General}

All chemicals and reagents were purchased from Merck, Fluka and Aldrich. Melting points were measured on an Electrothermal 9100 apparatus and are uncorrected. All the products were known compounds and were identified by comparison of their spectroscopic and analytical data with those authentic samples.

\subsection{Preparation of $\mathrm{H}_{5} \mathrm{PV}_{2} \mathrm{Mo}_{10} \mathrm{O}_{40} \mathrm{POM}$ composite}

Initially, $7.1 \mathrm{~g}$ of $\mathrm{Na}_{2} \mathrm{HPO}_{4}$ was dissolved in $100 \mathrm{~mL}$ of water and mixed with solution of 6.1 $\mathrm{g}$ of sodium metavanadate in $100 \mathrm{~mL}$ of boiling water. After that, the mixture was cooled and acidified to a red color with $5 \mathrm{~mL}$ of concentrated sulfuric acid. Then, a solution of $133 \mathrm{~g}$ of $\mathrm{Na}_{2} \mathrm{MoO}_{4} \cdot 2 \mathrm{H}_{2} \mathrm{O}$ in $200 \mathrm{~mL}$ of water was added to this mixture. Finally, $85 \mathrm{~mL}$ of 
concentrated sulfuric acid was added slowly with vigorous stirring of the solution. With this addition the dark red color changed to a lighter red. The synthesized heteropoly acid was then extracted with $400 \mathrm{~mL}$ of ethyl ether after the water solution was cooled. After separation, a stream of air was passed through the heteropoly etherate layer to free it of ether. The orange solid that remained was dissolved in $50 \mathrm{~mL}$ of water, concentrated to the first appearance of crystals in a vacuum desiccator over concentrated sulfuric acid. Then, it was allowed to crystallize further. The orange crystals that formed were filtered, washed with water, and air dried [12].

\subsection{Preparation of $\mathrm{H}_{5} \mathrm{PV}_{2} \mathrm{Mo}_{10} \mathrm{O}_{40} / \mathrm{SiO}_{2} \mathrm{POM}$ composite}

At first, $1.0 \mathrm{~g}$ of the synthesized $\mathrm{H}_{5} \mathrm{PV}_{2} \mathrm{Mo}_{10} \mathrm{O}_{40}$ was dissolved in $50 \mathrm{~mL}$ of water and the mixture was added to silica gel 60, (10 g, Merck, 0.040-0.063 mm, surface area 480-540 $\mathrm{m}^{2}$ $\mathrm{g}^{-1}$ ) which is suspended in $50 \mathrm{~mL}$ of water. After that, the resulting mixture was stirred at RT for $2 \mathrm{~h}$ and the water was then evaporated undervacuum. Finally, the finalized $\mathrm{H}_{5} \mathrm{PV}_{2} \mathrm{Mo}_{10} \mathrm{O}_{40} / \mathrm{SiO}_{2}$ was dried under reduced pressure for $2 \mathrm{~h}[11]$.

\subsection{General procedure for the synthesis of 2-substituted quinazolinones.}

A mixture of an aromatic aldehyde $(1.0 \mathrm{mmol})$ and anthranilamide $(1.0 \mathrm{mmol})$ and $\mathrm{H}_{5} \mathrm{PV}_{2} \mathrm{Mo}_{10} \mathrm{O}_{40} / \mathrm{SiO}_{2}$ composite $(0.3 \mathrm{~g})$ in $\mathrm{EtOH}(2 \mathrm{~mL})$ was stirred at room temperature. The completion of the reaction was monitored by thin layer chromatography (TLC). After completion of the reaction, the catalyst was filtered. Finally, after a short time, the product was precipitated in ethanol and no more purification was required.

\section{Results and discussion}

In this work, 2-substituted quinazolinone derivatives were synthesized by the reaction of different aromatic aldehydes with an anthranilamide in the presence of a catalytic amount of 
$\mathrm{H}_{5} \mathrm{PV}_{2} \mathrm{Mo}_{10} \mathrm{O}_{40} / \mathrm{SiO}_{2} \mathrm{POM}$ composite in ethanol at ambient temperature. The results are summarized in Table 1, from which it can be seen than all the utilized aldehydes supplied the desired products with great yields in short reaction times.

Table 1. Synthesis of 2-substituted quinazolinone derivatives in the presence of $\mathrm{H}_{5} \mathrm{PV}_{2} \mathrm{Mo}_{10} \mathrm{O}_{40} / \mathrm{SiO}_{2} \mathrm{POM}$ composite.

\begin{tabular}{lllllll}
\hline \multirow{2}{*}{ Entry } & $\mathrm{R}^{1}$ & Product & Time (min) & Yield $^{\mathrm{a}}(\%)$ & \multicolumn{2}{c}{$\mathrm{Mp}\left({ }^{\circ} \mathrm{C}\right)$} \\
\cline { 5 - 6 } & & & & & Found & Reported \\
\hline 1 & $\mathrm{C}_{6} \mathrm{H}_{5}$ & $\mathbf{2 a}$ & 65 & 86 & $244-246$ & $245-246[13]$ \\
2 & $4-\mathrm{MeC}_{6} \mathrm{H}_{4}$ & $\mathbf{2 b}$ & 90 & 82 & $237-238$ & $237-238[13]$ \\
3 & $4-\mathrm{BrC}_{6} \mathrm{H}_{4}$ & $\mathbf{2 c}$ & 55 & 98 & $317-318$ & $318[14]$ \\
4 & $4-\mathrm{ClC}_{6} \mathrm{H}_{4}$ & $\mathbf{2 d}$ & 55 & 95 & $299-300$ & $295-297[15]$ \\
5 & $4-\mathrm{MeOC}_{6} \mathrm{H}_{4}$ & $\mathbf{2 e}$ & 75 & 90 & $250-251$ & $246-247[13]$ \\
\hline
\end{tabular}

\section{Conclusions}

In summary, we have introduced $\mathrm{H}_{5} \mathrm{PV}_{2} \mathrm{Mo}_{10} \mathrm{O}_{40} / \mathrm{SiO}_{2} \mathrm{POM}$ composite for the synthesis of 2substituted quinazolinone derivatives. The efficient and selective syntheses of 2-substituted quinazolinone derivatives were carried out using different aromatic aldehydes and anthranilamide in the presence of a catalytic amount of $\mathrm{H}_{5} \mathrm{PV}_{2} \mathrm{Mo}_{10} \mathrm{O}_{40} / \mathrm{SiO}_{2} \mathrm{POM}$ composite in ethanol at room temperature in high yields.

\section{Acknowledgements}

The authors gratefully acknowledge the partial support from the Research Council of the Iran University of Science and Technology. 


\section{References}

1. Wang, S.S.; Yang, G.Y. Chem. Rev. 2015, 115, 4893.

2. Maleki, A. Tetrahedron 2012, 68, 7827.

3. Maleki, A.Tetrahedron Lett. 2013, 54, 2055.

4. Maleki, A. RSC Adv. 2014, 4, 64169.

5. Maleki, A.; Kamalzare, M. Catal. Commun. 2014, 53, 67.

6. Maleki, A.; Ghamari, N.; Kamalzare, M. RSC Adv. 2014, 4, 9416.

7. Maleki, A.; Aghaei. M.; Ghamari, N. Chem. Lett. 2015, 44, 259.

8. Maleki, A.; Kari, T.; Aghaei, M. J. Porous Mater. 2017, 24, 1481.

9. Maleki, A.; Rabbani, M.; Shahrokh, S. Appl. Organomet. Chem. 2015, 29, 809.

10. Maleki, A.; Hajizadeh, Z.; Firouzi-Haji, R. Micropor. Mesopor. Mater. 2018, 259, 46.

11. Khenkin, A.M.; Neumann, R. ChemSusChem 2011, 4, 346.

12. Tsigdinos, G.A.; Hallada, C.J. Inorg. Chem. 1968, 7, 437.

13. Feng, Y.; Li, Y.; Cheng, G.; Wang, L.; Cui, X. J. Org. Chem. 2015, 80, 7099.

14. Rostamizadeh, S.; Nojavan, M.; Aryan, R.; Isapoor, E.; Azad, M. J. Mol. Catal. A 2013, 374, 102 .

15. Wang, L.X.; Xiang, J. F.; Tang, Y. L. Eur. J. Org. Chem. 2014, 2014, 2682. 